\title{
Molecular analysis, biofilm formation, and susceptibility of methicillin-resistant Staphylococcus aureus strains causing community- and health care-associated infections in central venous catheters
}

\author{
Muhammad Sohail ${ }^{[1]}$ and Zakia Latif ${ }^{[1]}$
}

[1]. Department of Microbiology and Molecular Genetics, Quaid-e-Azam Campus, University of the Punjab, Lahore, Pakistan.

\begin{abstract}
Introduction: The behavior of methicillin-resistant Staphylococcus aureus (MRSA) isolated from central venous catheterrelated infection was evaluated to determine its biofilm potential, antimicrobial resistance, and adhesion genes. Methods: A total of 1,156 central venous catheters (CVC) were evaluated to screen for pathogens. Antimicrobial sensitivity, biofilm formation potential, and molecular analysis of MRSA were examined following standard guidelines. Results: Of the 1,156 samples, 882 (76\%) were colonized by bacteria or candida. Among the infected patients, $69 \%$ were male and $36 \%$ were female with median age of 32 years. Staphylococcus aureus infected 39\% (344/882) of CVCs in patients. Of the 59\% (208/344) of patients with MRSA, 57\% had community acquired MRSA and 43\% had hospital acquired MRSA. Linezolid and vancomycin killed $100 \%$ of MRSA; resistance levels to fusidic acid, doxycycline, clindamycin, azithromycin, amikacin, trimethoprim-sulfamethoxazole, gentamycin, tobramycin, and ofloxacin were $21 \%, 42 \%, 66 \%, 68 \%, 72 \%, 85 \%, 95 \%, 97 \%$, and $98 \%$ respectively. Strong biofilm was produced by $23 \%$ of samples, moderate by $27 \%$, and weak by $50 \%$ of MRSA. The presence of adhesion genes, $s d r \mathrm{C}$ and $s d r \mathrm{D}(90 \%)$, eno $(87 \%)$, fnbA (80\%), clf A and $s d r \mathrm{E}(67 \%), f n b \mathrm{~B}, s d r \mathrm{D}(61 \%)$, and $c n a(51 \%)$, in most MRSA samples suggested that the adhesion genes are associated with biofilm synthesis. Conclusions: The superbug MRSA is a major cause of CVCrelated infection. Antibiotic resistance to major classes of antibiotics and biofilm formation potential enhanced superbug MRSA virulence, leading to complicated infection. MRSA causes infection in hospitals, communities, and livestock.
\end{abstract}

Keywords: Community acquired MRSA. Hospital acquired MRSA. Central venous catheter.

Antimicrobial resistance. Biofilm and adhesion genes.

\section{INTRODUCTION}

Drug resistance bacteria kill 700,000 people per year and this value is expected to reach 1 million in $2050^{1}$. Central venous catheters (CVCs) are indispensable in modern medicine practices, particularly in intensive care unit (ICU) patients. CVCs facilitate health management of critical patients who requires intermittent medication, fluids, and food ${ }^{2}$. CVC indwelling patients are at a high risk of mortality and morbidity along with other complications such as bloodstream infection and cardiac arrhythmia. Approximately $78 \%$ of critically ill patients require some type of CVC and $90 \%$ of catheter-related blood stream infections are -CVC related ${ }^{3}$. Two-thirds of these infections are caused by Gram-positive bacteria, predominantly Gram-positive cocci which are equally responsible for

Corresponding author: Dr. Muhammad Sohail.

e-mail: drsohailmmg@gmail.com

Received 27 October 2017

Accepted 18 July 2018 infections in ICU and non-ICU patients ${ }^{4}$. CVCs are colonized by microorganisms including Staphylococcus aureus, which is the most common cause of CVC infections ${ }^{5-7}$. Staphylococcus aureus is responsible for septic shock in $30 \%$ of CVC-associated septicemia cases ${ }^{8}$. Both types of MRSA, community acquired (CA-MRSA) and hospital acquired (HA-MRSA), infect hospitalized and non-hospitalized individuals ${ }^{9,10}$. Resistance to a large range of antibiotics complicates MRSA infection and increase the potential for biofilm formation on biotic and abiotic surfaces. Biofilms are complex heterogeneous structures with fluid-filled tunnels ${ }^{11}$. Interestingly, $60 \%$ of catheter-related infections are caused by biofilm-producing bacteria ${ }^{12}$. Microbial surface components recognizing adhesive matrix molecules of MRSA mediate attachment to host molecules and are potentially involved in biofilm formation ${ }^{13,14}$. Microbial surface components recognizing adhesive matrix molecules include fibronectinbinding proteins ( $f n b \mathrm{~A}$ and $f n b \mathrm{~B})$, clumping factors ( $c l f \mathrm{~A}$ and $c l f \mathrm{~B})$, collagen-binding protein ( $\mathrm{cna}$ ), fibrinogen-binding protein (fib), laminin-binding protein (eno), and three Sdr proteins $(s d r \mathrm{C}, s d r \mathrm{D} \text {, and } s d r \mathrm{E})^{13,15}$. Staphylococcus aureus is found in $30 \%$ of healthy people, who are healthy carriers of infection ${ }^{16}$. 
Staphylococcus aureus harbors a variety of pathogenic tools, enzymes, and toxins that cause minor to life-threatening infections ${ }^{17}$. This bacterium is a causative agent of infections on biomedical device- and surgical tube-related infections, which greatly increase mortality, mortality, costs of treatment, and hospital stays. Conventional antibiotics are not effective against biofilm, worsening the situation ${ }^{18}$. Pathogenic tools, rapidly acquired resistance, and rapid mutation development are leading causes of methicillin-resistant Staphylococcus aureus (MRSA) as epidemic infectious agents ${ }^{19,20}$.

The goal of this study was to isolate and identify the pathogens causing CVC-related infections and determine the antibiogram, biofilm potential, and adhesion genes in superbug MRSA.

\section{METHODS}

This study was conducted using 1,156 CVC samples collected from April 2012 to April 2016. The specimens studied were CVC tips, femoral, Jugular, and subclavian catheters. CVC specimens were processed as described by Maki et. al. ${ }^{21}$ with slight modifications ${ }^{21}$. Briefly, catheter tips were cut into two pieces $5 \mathrm{~cm}$ in length; one piece was directly rolled on culture plates and the other was incubated for $1 \mathrm{~h}$ in a tube containing $1 \mathrm{~mL}$ brain heart infusion [(BHI); Oxoid, Cheshire, UK]. Next, the samples were centrifuged and the pellet containing pathogens was inoculated on Sheep Blood Agar [(SBA); Oxoid], Chocolate [(CHO); Oxoid] agar, Sabouraud dextrose agar [(SDA); Oxoid], and MacConkey [(MAC; Oxoid] agar. All plates were examined after $24-\mathrm{h}$ incubation at $37^{\circ} \mathrm{C}$ and further incubated for 48 and $72 \mathrm{~h}$ if no growth was evident. The acceptable cut-off to declare CVC-related infection was 15 colony-forming units per milliliter $(\mathrm{cfu} / \mathrm{mL})$ after overnight incubation ${ }^{22}$. After preliminary identification of pathogens, Staphylococcus aureus was confirmed based on a high salt concentration, deoxyribonuclease (DNase) production, and mannitol fermentation. The same bacteria isolated from both techniques (direct and enrichment) were considered as pathogenic and further analyzed.

\section{Antimicrobial sensitivity test}

The Kirby-Bauer disk diffusion method was used for the antibiogram of $S$. aureus against eight classes of antibiotics following the performance guidelines and breakpoints recommended by Clinical and Laboratory Standards Institute (CLSI) ${ }^{23}$. Staphylococcus aureus (ATCC 29213) was used as a control strain for antibiogram. Based on cefoxitin $(30 \mu \mathrm{g})$ resistance (zone of inhibition $\leq 21 \mathrm{~nm}$ ), $S$. aureus was declared as MRSA and confirmed by amplification of $m e e^{23}$. The minimum inhibitory concentration of vancomycin was measured by the E-test (bioMérieux, Marcy-l'Étoile, France) following CLSI guidelines.

\section{Slime production}

Congo red agar was used to evaluate the slime production capability of MRSA isolated form CVC-related infections ${ }^{24}$. Red colonies were categorized as non-slime producers and black colonies as slime producers. The intensity of the black color was directly related to the slime production capability.

\section{Quantitative biofilm formation on polystyrene}

Biofilm formation was measured quantitatively by the crystal violet assay as described by O'Toole with some modifications ${ }^{25}$. Briefly, a fresh bacterial culture was diluted by 200 -fold in BHI containing $1 \%$ glucose and then inoculated into a 96 -well polystyrene plate. The plate was incubated aerobically at $37^{\circ} \mathrm{C}$ for $48 \mathrm{~h}$ without agitation with a positive ( $S$. aureus ATCC 35556) and negative (Staphylococcus epidermidis ATCC 12228) control strain. Plates were washed three times with phosphatebuffered saline, dried at room temperature, and stained with $0.1 \%(\mathrm{w} / \mathrm{v})$ crystal violet $(\mathrm{CV})$ for $10 \mathrm{~min}$. After washing three times with phosphate-buffered saline, $\mathrm{CV}$ was solubilized by $95 \%$ ethanol for $10 \mathrm{~min}$ and the optical density (OD) was measured at $595 \mathrm{~nm}$. The biofilm formation index (BFI) was measured using the following equation ${ }^{26}: \mathrm{BFI}=(\mathrm{AB}-\mathrm{CW}) / \mathrm{G}$.

The OD of CV-stained attached bacteria was denoted as $\mathrm{AB}$. CW represents the $\mathrm{OD}$ of the $\mathrm{CV}$-stained negative control containing only broth medium. G denotes the OD of planktonic bacteria. Based on the ODs values, microorganisms were classified as weak $(0.1>\mathrm{BFI} \leq 0.5)$, moderate $(0.5>\mathrm{BFI} \leq 1)$, and strong $(\mathrm{BFI}>1)$ biofilm producers. MRSA with an OD of less than 0.1 were classified as non-biofilm producers ${ }^{27}$.

\section{Extraction of genomic DNA}

Genomic deoxyribonucleic acid (DNA) was extracted using a conventional method ${ }^{28}$. Bacteria were grown overnight in BHI at $37^{\circ} \mathrm{C}$ in a shaking incubator and harvested by centrifugation. The pellet was incubated at $37^{\circ} \mathrm{C}$ for $1 \mathrm{~h}$ in $10 \mathrm{mM}$ Tris-HCL and $34.5 \mathrm{mg} / \mathrm{mL}$ lysozyme (Sigma, St. Louis, MO, USA). Lysis was conducted by incubation in lysis buffer containing $50 \mathrm{mM}$ Tris, $100 \mathrm{mM}$ ethylenediaminetetraacetic acid (EDTA), 1\% SDS, $20 \mu \mathrm{L}$ proteinase $\mathrm{k}$ (Sigma), and lysostaphin (Sigma) at $55^{\circ} \mathrm{C}$ for $1 \mathrm{~h}$. DNA was eluted in DNase-free water after extraction and ethanol precipitation. The concentration was measured with a NanoDrop ${ }^{\mathrm{TM}}$ (Thermo Scientific, Waltham, MA, USA) and stored at $4^{\circ} \mathrm{C}$ until further investigation.

\section{Prevalence of adhesion genes of MRSA}

A total of 203 MRSA isolates were screened for 10 different adhesion genes (clfA, clf $\mathrm{B}$, eno, cna, fnbA, $f n b \mathrm{~B}, f i b, s d r \mathrm{C}, s d r \mathrm{D}, s d r \mathrm{E}), m e c$, and Panton-Valentine leucocidin. The following primers were used in this study: MecA-R (ATGCGCTATAGATTGAAAGGAT) and MecA-F (GTGAAGATATACCAAGTGATT) 310 base pairs (bp) ${ }^{29}$; Luk-PV2 (GCATCAAGTGTATTGGATAGCAAAAGC) and Luk-PV1 (ATCATTAGGTAAAATGTCTGGACATGATCCA) 433bp ${ }^{29}$; FnbA-R (TGTGCTTGACCATGCTCTTC) and FnbA-F (GATACAAACCCAGGTGGTGG) 191 bp $^{30}$; FnbB-R (CAAGTTCGATAGGAGTACTATGTTC) and FnbB-F (GTAACAGCTAATGGTCGAATTGATAC) 524bp; Cna-R (AATCAGTAATTGCACTTTGTCCACTG) and Cna-F (GTCAAGCAGTTATTAACACCAGAC) $423 \mathrm{bp}^{31}$; clfA-R (AGGCACTGAAAAACCATAATTCA) and clfA-F (TTACGAATCAGTTGACGAATGTG) 104bp ${ }^{32}$; clfB-R (CCGTCGGTTGAGGTGTTTCATTTG) and clfB-F (TGCAAGTGCAGATTCCGAAAAAAAC) 
194bp ${ }^{33}$; eno-R (CAACAGCATCTTCAGTACCTTC) and eno-F (ACGTGCAGCAGCTGACT) 302 bp ${ }^{34}$; fib-R (GCTCTTGTAAGACCATTTTCTTCAC) and fib-F (CTACAACTACAATTGCGTCAACAG) 404bp ${ }^{34}$; SdrC-R (ACGACTATTAAACCAAGAAC) and SdrC-F (TTCGCACTGTTTGTGTTTGCAC) 560 bp ${ }^{35}$; SdrD-R (GGAAATAAAGTTGAAGTTTC) and SdrD-F (GTACTTGAAATAAGCGGTTG) 500bp $\mathrm{p}^{35}$; SdrE-R (CAGTAAATGTGTCAAAAGA) and SdrE-F (ACTTTGTCATCAACTGTAAT) 767bp ${ }^{35}$.

\section{RESULTS}

Among the 1,156 CVC samples, 882 (76\%) were colonized with pathogens, while 274 (24\%) CVC tips were negative for pathogens. The results of both inoculation techniques were compared for pathogen confirmation. Same microorganisms isolated from both techniques were considered as pathogens.

\section{Prevalence of MRSA among CVC-related infections}

Of the 882 CVCs colonized with pathogens, $64 \%(564 / 882)$ were due to Gram-positive bacteria, $26 \%(230 / 882)$ by Gramnegative bacteria, and 10\% (88/882) by Candida. Among Grampositive bacteria, S. aureus (39\%) and coagulase-negative $S$. aureus (16\%) were dominant. Among Gram-negative bacteria, Klebsiella pneumoniae (10\%) and Pseudomonas aeruginosa (7\%) were the most common. Of S. aureus, 59\% (203/344) were MRSA. Among the 203 patients infected by MRSA, 129 $(64 \%)$ were male and $74(36 \%)$ were female with a combined mean age of $32 \pm 3$ years. Of MRSA isolated from CVC, $57 \%$ (116/203) were CA-MRSA and 43\% (87/203) were HA-MRSA (Figure 1), which were categorized based on CDC criteria (CA-MRSA harbors $p c v$ and $S C C m e c$ IV/V) ${ }^{36}$. The prevalence of MRSA over 4 years is shown in Table 1 with respect to age and gender. The age group 20-29 years was most commonly

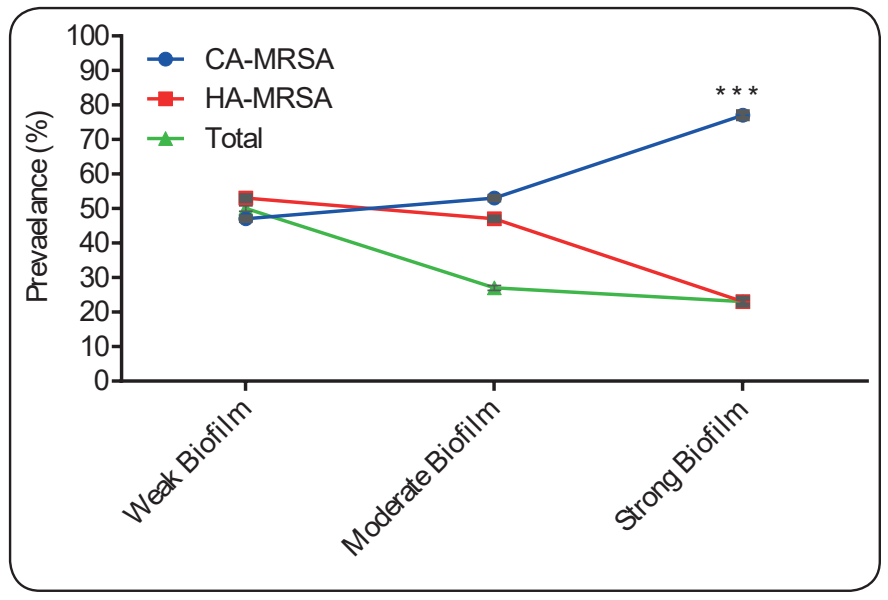

FIGURE 1: Biofilm formation potential between HA-MRSA and CA-MRSA. CA-MRSA: community acquired methicillin resistance Staphylococcus aureus; HA-MRSA: Hospital acquired methicillin resistance Staphylococcus aureus.

infected with MRSA, followed by the age groups of 40-49 and $30-39$ years with infection rates of $63 \%, 30 \%$, and $28 \%$, respectively.

\section{Antimicrobial sensitivity testing and biofilm production by MRSA}

Antimicrobial sensitivity testing results are shown in Figure 2 for CA-MRSA and HA-MRSA. Briefly, 72\% (146/203) of MRSA samples were resistant to amikacin, $94 \%(192 / 203)$ to gentamicin, $97 \%(197 / 203)$ to tobramycin, $68 \%(138 / 203)$ to azithromycin, $42 \%(85 / 203)$ to doxycycline, $98 \%(199 / 203)$ to ciprofloxacin and ofloxacin, 85\% (172/203) to trimethoprimsulfamethoxazole (SXT), 66\% (134/203) to clindamycin, and $21 \%(43 / 203)$ to fusidic acid. No isolates showed resistance to linezolid and vancomycin.

TABLE 1: Prevalence of MRSA in CVC infections.

\begin{tabular}{|c|c|c|c|c|c|}
\hline Item & $\begin{array}{l}2013 \\
\text { n (\%) }\end{array}$ & $\begin{array}{l}2014 \\
\text { n (\%) }\end{array}$ & $\begin{array}{l}2015 \\
\text { n (\%) }\end{array}$ & $\begin{array}{l}2016 \\
\text { n (\%) }\end{array}$ & $\begin{array}{l}\text { Total } \\
\text { n (\%) }\end{array}$ \\
\hline Patients & 41 & 53 & 44 & 65 & 203 \\
\hline female & $17(41.0)$ & $20(38.0)$ & $18(41.0)$ & $19(29.0)$ & $74(36.0)$ \\
\hline \multicolumn{6}{|l|}{ Age } \\
\hline$<10$ & $5(12.0)$ & $12(23.0)$ & $5(11.0)$ & $3(5.0)$ & $25(12.0)$ \\
\hline 20-29 & $9(22$. & $14(26.0)$ & $19(43.0)$ & $21(32.0)$ & $63(31.0)$ \\
\hline 30-39 & $9(22.0)$ & $6(11.0)$ & $7(16.0)$ & $6(9.0)$ & $28(14.0)$ \\
\hline $40-49$ & $8(20.0)$ & $9(17.0)$ & $1(2.0)$ & $12(18.0)$ & $30(15.0)$ \\
\hline 50-59 & $3(7.0)$ & $7(13.0)$ & $4(10.0)$ & $9(14.0)$ & $23(11.0)$ \\
\hline$\geq 60$ & $6(15.0)$ & $4(8.0)$ & $2(4.0)$ & $9(14.0)$ & $21(10.0)$ \\
\hline
\end{tabular}

MRSA: methicillin resistance Staphylococcus aureus; CVC: central venous catheters; CA-MRSA: community acquired methicillin resistance Staphylococcus aureus; HA-MRSA: hospital acquired methicillin resistance Staphylococcus aureus. 


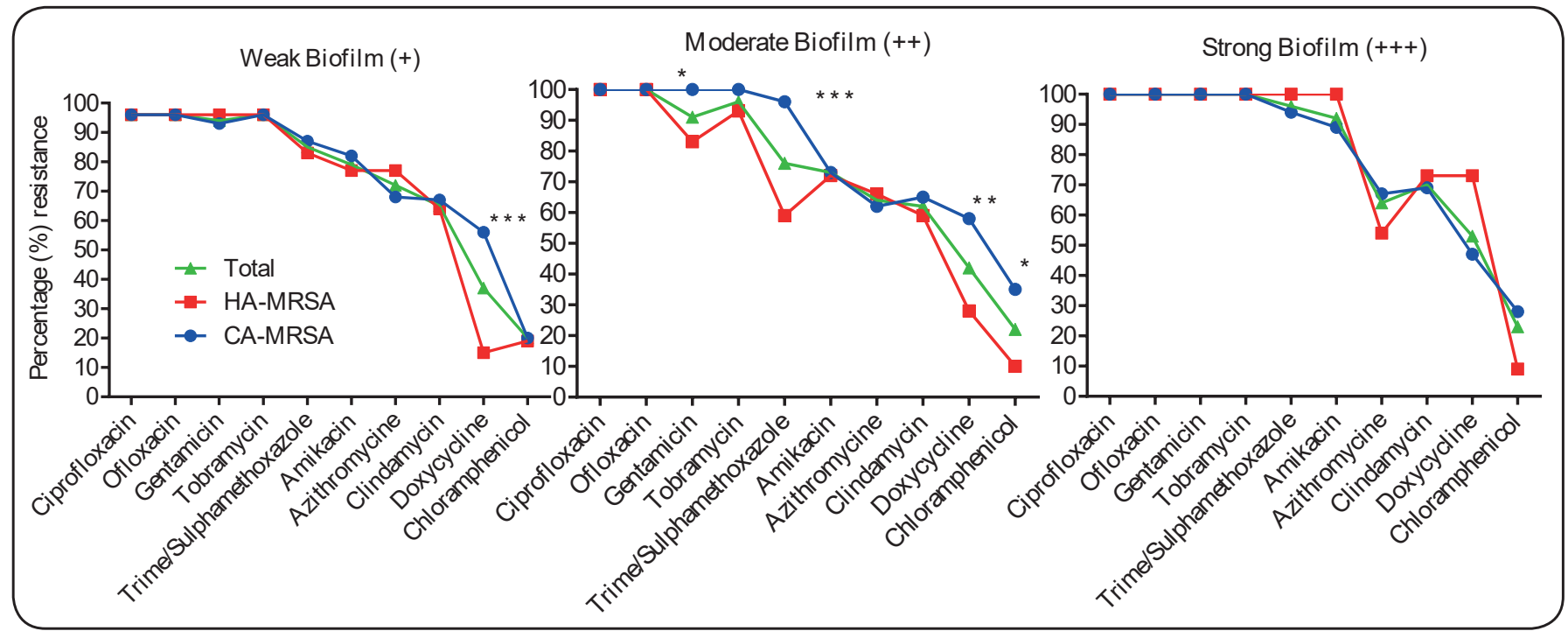

FIGURE 2: Prevalence of resistance between HA-MRSA and CA-MRSA. HA-MRSA: Hospital acquired methicillin resistance Staphylococcus aureus; CAMRSA: community acquired methicillin resistance Staphylococcus aureus.

All MRSA isolated from CVC were biofilm producers. Half of MRSA (50\%) were weak biofilm producers followed by moderate $(27 \%)$ and strong biofilm $(23 \%)$ producers.

\section{Prevalence of adhesion genes of MRSA}

Ten adhesion genes were amplified using specific terminal sequences. The amplification results showed that $c l f \mathrm{~B}$ was present in all isolates of MRSA, followed by $s d r \mathrm{C}$ and $s d r \mathrm{D}$ (90\%), eno (87\%), fnbA (80\%), clfA and $s d r \mathrm{E}(67 \%), f n b \mathrm{~B}$ and $s d r \mathrm{D}(61 \%)$, and cna (51\%). For moderate and weak biofilm producers, no significant $(\mathrm{p}>0.05)$ differences were found among different types of MRSA (CA-MRSA, HA-MRSA) and the presence of adhesion genes (Table 2). However, for strong biofilm, there was a significant $(\mathrm{p}<0.05)$ difference between the types of MRSA (CA-MRSA and HA-MRSA) because of the presence of adhesion genes.

\section{Statistical analysis}

All tests were performed in duplicate with a confidence level of $95 \%$ and significance level of $<0.05$. Statistical Package for the Social Sciences (SPSS) software (SPSS, Inc., Chicago, IL, USA) was used for data analysis with the Chi-square test.

\section{DISCUSSION}

Antimicrobial resistance is a major threat to people and worsens when lifesaving devices become contaminated. CVC is essential for critically ill patients but leads to life-threatening consequences when inserted in the central venous system ${ }^{37}$ and become colonized by multidrug-resistant superbugs such as MRSA.

This study evaluated CVC-related infections on different types of catheters and hospital units and directly involving CVC rather than blood culture. This study revealed that age, gender, and sex were not significant predictors of CVC-related infections. Interestingly, Gram-negative bacteria outnumbered $S$. aureus in causing CVC infection.

This study revealed that $76 \%$ of CVCs were infected by bacteria ( $63 \%$ by Gram-positive) or candida; a similar study conducted in Italy showed that $73 \%$ of all CVCs from ICU patients were infected and 54\% were due to Gram-positive bacteria $^{38}$.

Staphylococcus aureus is the major pathogen causing CVC infections (39\%), followed by CONS (16\%) and K. pneumoniae $(10 \%)$. These results agree with those of previous studies ${ }^{39,40}$. Most studies demonstrated that Gram-negative bacteria are the major cause of catheter-related blood stream infection, but these studies used blood samples to detect infection. A surveillance study in Australia revealed that Enterococci species is a major pathogen $(26 \%)$ of central line catheter-related infection ${ }^{41}$. The prevalence of MRSA $(59 \%$; 203/344) among CVC-related infections agreed with the results of previous similar studies ${ }^{42,43}$. In India, $P$. aeruginosa was found to be the most common cause $(42 \%)$ of CVC infection, which contradicted our study because the previous study was conducted in only cancer patients ${ }^{44}$.

Our study revealed that $57 \%$ of MRSA infections were due to HA-MRSA, which disagreed with the results of a singlecenter study conducted in France in 2012 which showed that $34 \%$ of CVC-related infections were caused by HA-MRSA ${ }^{45}$. CA-MRSA is also emerging as a notorious pathogen in CVCrelated infections, particularly in children ${ }^{45}$.

Biofilm producers are more resistant to antibiotics than their counterparts ${ }^{46}$. All isolates were sensitive to vancomycin and linezolid, which agrees with previous studies ${ }^{47}$. Among MRSA cases, $85 \%$ were resistant to SXT, which agrees with the literature ${ }^{47}$. Among macrolides, erythromycin resistance was observed in $96 \%$ of cases and ciprofloxacin resistance in $98 \%$ of MRSA isolates, which agrees with studies conducted in $\mathrm{Japan}^{48,49}$. The same studies showed different resistance to SXT 
TABLE 2: Prevalence of adhesion genes in MRSA isolated from CVC related infection.

\begin{tabular}{|c|c|c|c|c|c|c|c|c|c|c|}
\hline Adhesion genes & clfA & clfB & eno & cna & $f n b A$ & $f n b B$ & fib & sdrC & sdrD & sdrE \\
\hline \multicolumn{11}{|l|}{ Biofilm weak (+) } \\
\hline Total & $\begin{array}{c}69 \% \\
(70 / 101)\end{array}$ & $\begin{array}{c}100 \% \\
(101 / 100)\end{array}$ & $\begin{array}{c}83 \% \\
(84 / 101)\end{array}$ & $\begin{array}{c}60 \% \\
(61 / 101)\end{array}$ & $\begin{array}{c}83 \% \\
(84 / 101)\end{array}$ & $\begin{array}{c}66 \% \\
(67 / 101)\end{array}$ & $\begin{array}{c}91 \% \\
(92 / 101)\end{array}$ & $\begin{array}{c}91 \% \\
(92 / 101)\end{array}$ & $\begin{array}{c}66 \% \\
(67 / 101)\end{array}$ & $\begin{array}{c}68 \% \\
(69 / 101)\end{array}$ \\
\hline CA-MRSA & $\begin{array}{c}43 \% \\
(30 / 70)\end{array}$ & $\begin{array}{c}47 \% \\
(47 / 101)\end{array}$ & $\begin{array}{c}45 \% \\
(38 / 84)\end{array}$ & $\begin{array}{c}66 \% \\
(40 / 61)\end{array}$ & $\begin{array}{c}45 \% \\
(38 / 84)\end{array}$ & $\begin{array}{c}42 \% \\
(28 / 67)\end{array}$ & $\begin{array}{c}47 \% \\
(43 / 92)\end{array}$ & $\begin{array}{c}46 \% \\
(42 / 92)\end{array}$ & $\begin{array}{c}42 \% \\
(28 / 67)\end{array}$ & $\begin{array}{c}45 \% \\
(31 / 69)\end{array}$ \\
\hline HA-MRSA & $\begin{array}{c}57 \% \\
(40 / 70)\end{array}$ & $\begin{array}{c}54 \% \\
(54 / 101)\end{array}$ & $\begin{array}{c}54 \% \\
(46 / 84)\end{array}$ & $\begin{array}{c}34 \% \\
(21 / 61)\end{array}$ & $\begin{array}{c}55 \% \\
(46 / 84)\end{array}$ & $\begin{array}{c}58 \% \\
(39 / 67)\end{array}$ & $\begin{array}{c}49 \% \\
(53 / 92)\end{array}$ & $\begin{array}{c}54 \% \\
(50 / 92)\end{array}$ & $\begin{array}{c}58 \% \\
(39 / 67)\end{array}$ & $\begin{array}{c}55 \% \\
(38 / 69)\end{array}$ \\
\hline \multicolumn{11}{|c|}{ Biofilm moderate $(++)$} \\
\hline Total & $\begin{array}{c}71 \% \\
(39 / 55)\end{array}$ & $\begin{array}{c}100 \% \\
(55 / 55)\end{array}$ & $\begin{array}{c}89 \% \\
(48 / 55)\end{array}$ & $\begin{array}{c}46 \% \\
(25 / 55)\end{array}$ & $\begin{array}{c}76 \% \\
(42 / 55)\end{array}$ & $\begin{array}{c}51 \% \\
(28 / 55)\end{array}$ & $\begin{array}{c}89 \% \\
(49 / 55)\end{array}$ & $\begin{array}{c}87 \% \\
(48 / 88)\end{array}$ & $\begin{array}{c}51 \% \\
(28 / 55)\end{array}$ & $\begin{array}{c}64 \% \\
(35 / 55)\end{array}$ \\
\hline CA-MRSA & $\begin{array}{c}46 \% \\
(18 / 39)\end{array}$ & $\begin{array}{c}53 \% \\
(29 / 55)\end{array}$ & $\begin{array}{c}53 \% \\
(26 / 49)\end{array}$ & $\begin{array}{c}84 \% \\
(21 / 25)\end{array}$ & $\begin{array}{c}55 \% \\
(23 / 42)\end{array}$ & $\begin{array}{c}57 \% \\
(16 / 28)\end{array}$ & $\begin{array}{c}53 \% \\
(29 / 49)\end{array}$ & $\begin{array}{c}52 \% \\
(25 / 48)\end{array}$ & $\begin{array}{c}57 \% \\
(16 / 28)\end{array}$ & $\begin{array}{c}54 \% \\
(19 / 35)\end{array}$ \\
\hline HA-MRSA & $\begin{array}{c}54 \% \\
(21 / 39)\end{array}$ & $\begin{array}{c}47 \% \\
(26 / 55)\end{array}$ & $\begin{array}{c}47 \% \\
(23 / 49)\end{array}$ & $\begin{array}{c}16 \% \\
(4 / 25)\end{array}$ & $\begin{array}{c}45 \% \\
(19 / 42)\end{array}$ & $\begin{array}{c}43 \% \\
(12 / 28)\end{array}$ & $\begin{array}{c}47 \% \\
(23 / 49)\end{array}$ & $\begin{array}{c}48 \% \\
(23 / 48)\end{array}$ & $\begin{array}{c}43 \% \\
(12 / 28)\end{array}$ & $\begin{array}{c}46 \% \\
(16 / 35)\end{array}$ \\
\hline \multicolumn{11}{|c|}{ Biofilm strong $(+++)$} \\
\hline Total & $\begin{array}{c}57 \% \\
(27 / 47)\end{array}$ & $\begin{array}{c}100 \% \\
(47 / 47)\end{array}$ & $\begin{array}{c}94 \% \\
(44 / 47)\end{array}$ & $\begin{array}{c}36 \% \\
(17 / 47)\end{array}$ & $\begin{array}{c}79 \% \\
(37 / 47)\end{array}$ & $\begin{array}{c}60 \% \\
(28 / 47)\end{array}$ & $\begin{array}{c}90 \% \\
(42 / 47)\end{array}$ & $\begin{array}{c}92 \% \\
(43 / 47)\end{array}$ & $\begin{array}{c}60 \% \\
(28 / 47)\end{array}$ & $\begin{array}{c}68 \% \\
(32 / 47)\end{array}$ \\
\hline CA-MRSA* & $\begin{array}{c}22 \% \\
(6 / 27)\end{array}$ & $\begin{array}{c}23 \% \\
(11 / 47)\end{array}$ & $\begin{array}{c}23 \% \\
(10 / 44)\end{array}$ & $\begin{array}{c}65 \% \\
(11 / 17)\end{array}$ & $\begin{array}{c}24 \% \\
(9 / 37)\end{array}$ & $\begin{array}{c}25 \% \\
(7 / 28)\end{array}$ & $\begin{array}{c}24 \% \\
(10 / 42)\end{array}$ & $\begin{array}{c}23 \% \\
(10 / 43)\end{array}$ & $\begin{array}{c}25 \% \\
(7 / 28)\end{array}$ & $\begin{array}{c}25 \% \\
(8 / 32)\end{array}$ \\
\hline HA-MRSA* & $\begin{array}{c}78 \% \\
(21 / 27)\end{array}$ & $\begin{array}{c}77 \% \\
(36 / 47)\end{array}$ & $\begin{array}{c}77 \% \\
(34 / 47)\end{array}$ & $\begin{array}{c}35 \% \\
(6 / 17)\end{array}$ & $\begin{array}{c}76 \% \\
(28 / 47)\end{array}$ & $\begin{array}{c}75 \% \\
(21 / 28)\end{array}$ & $\begin{array}{c}76 \% \\
(32 / 42)\end{array}$ & $\begin{array}{c}77 \% \\
(33 / 43)\end{array}$ & $\begin{array}{c}75 \% \\
(21 / 28)\end{array}$ & $\begin{array}{c}75 \% \\
(24 / 32)\end{array}$ \\
\hline
\end{tabular}

MRSA: methicillin resistance Staphylococcus aureus; CVC: central venous catheters; clfA: clumping factors A; clfB: clumping factors B; eno: laminin-binding protein; can: collagen-binding protein; fnbA: fibronectin binding protein A; fnbB: fibronectin binding protein B; fib: fibrinogen-binding protein; sdrC: serine aspartate peptide C ;sdrD: serine aspartate peptide D; sdrE: serine aspartate peptide E; CA-MRSA: community acquired methicillin resistance Staphylococcus aureus; HA-MRSA: Hospital acquired methicillin resistance Staphylococcus aureus. *Strong significant $P<0.01$;

$(2 \%)$ and clindamycin $(90 \%)$ because of the use of antibiotics in different settings $\mathrm{s}^{50,51}$. Variable resistance to fusidic acid was reported previously, and some reports showed the same resistance found in this study ${ }^{52}$. Similar fusidic acid resistance results were reported by Decousser ${ }^{53}$. Our study revealed a $42 \%$ resistance rate to doxycycline, while previous studies reported higher resistance ${ }^{54,55}$. For weak biofilm producers, there was a significant $(p<0.05)$ relationship between the type of MRSA (CA-MRSA and HA-MRSA) and doxycycline resistance. For moderate biofilm producers, a significant relationship $(p<0.05)$ was found for gentamycin, fusidic acid, doxycycline, and trimethoprim-sulfamethoxazole. For strong biofilm producers, both were equally resistance to antibiotics $(p>0.05)$. MRSA is well-known to thrive under antibiotic treatment. The variable resistance pattern to MRSA explains why antibiotics usage differs according to local guidelines in different locations. First-line drugs are more resistant because their use is common than other antibiotics. An imbalance has been detected among antibiotic usage, the discovery of new antibiotics, and emergence of resistance, which leads to serious consequences of infectious diseases ${ }^{56,57}$.

No significant difference was evident between weak and moderate biofilm producing MRSA via adhesion genes $(p>0.05)$. Interestingly, a significant difference was observed between the strong biofilm producers CA-MRSA and HAMRSA because of the adhesion genes evaluated in this study $(p<0.01)$. Twenty-five isolates contained all of the adhesion genes, suggesting that adhesion genes were exclusively involved in biofilm formation ${ }^{58}$. No gene or set of genes can function as a sole indicator of biofilm formation potential; this outcome supports previous findings ${ }^{59}$. A study conducted in Morocco revealed adhesion genes prevalence rates of $96 \% \mathrm{fnb} A, 60 \%$ eno, $43 \%$ clf $A, 43 \%$ clfB, $11 \%$ cna, $6 \%$ fib , and $2 \%$ fnbB in MRSA isolated from clinical specimens. These results contradicted our findings because these studies used different specimens to isolate the pathogens ${ }^{58,60}$. The results of the prevalence of adhesion genes among MRSA agrees with those of previous studies ${ }^{61,62}$. The presence of adhesion genes in most MRSA isolated from CVC-related infection was complementary to biofilm formation and posed resistance to antibiotics.

This study revealed a significant difference among the strength of biofilm potential, type of MRSA, and antibiotic resistance. The strong biofilm producers CA-MRSA and HAMRSA are equally resistant to antibiotics. Adhesion genes are indispensable for biofilm formation. The presence of adhesion genes is independent of biofilm strength. 


\section{Acknowledgments}

We thank Dr. Omer Chughtai for providing technical support in the development and implementation of this study.

\section{Conflict of interest}

The authors declare that there is no conflict of interest.

\section{Financial support}

This project is funded by the Higher Education Commission, Pakistan under Grant number 112-22691-2BM1-376.

\section{REFERENCES}

1. Meera Senthilingam, StC. Protecting the world from deadly superbugs. 2018; Available from: http://www.cnn.com/2016/05/23/ health/stopping-superbugs/index.html.

2. Tejedor SC, Tong D, Stein J, Payne C, Dressler D, Xue W, et al. Temporary central venous catheter utilization patterns in a large tertiary care center tracking the "idle central venous catheter". Infect Control Hosp Epidemiol. 2012;33(1)50-7.

3. Mermel LA. Prevention of intravascular catheter-related infections. Ann intern med. 2000;132(5)391-402.

4. Eggimann P, Pittet D. Overview of catheter $\square$ related infections with special emphasis on prevention based on educational programs. Clin Microbiol Infect. 2002;8(5)295-309.

5. Raad I. Intravascular-catheter-related infections. The Lancet. 1998;351(9106)893-8.

6. Elliott TS, Moss HA, Tebbs SE, Wilson IC, Bonser RS, Graham $\mathrm{TR}$, et al. Novel approach to investigate a source of microbial contamination of central venous catheters. Eur J Clin Microbiol Infect Dis. 1997;16(3)210-3.

7. Raad II, Sabbagh MF, Rand KH, Sherertz RJ. Quantitative tip culture methods and the diagnosis of central venous catheter-related infections. Diagn microbiol infect dis. 1992;15(1)13-20.

8. Bock SN, Lee RE, Fisher B, Rubin JT, Schwartzentruber DJ, Wei $\mathrm{JP}$, et al. A prospective randomized trial evaluating prophylactic antibiotics to prevent triple-lumen catheter-related sepsis in patients treated with immunotherapy. J Clin Oncol. 1990;8(1)161-9.

9. Centers for Disease Control and Prevention. Four pediatric deaths from community-acquired methicillin-resistant Staphylococcus aureus - Minnesota and North Dakota, 1997-1999. MMWR. Morb Mortal Wkly Rep. 1999;48(32)707-10.

10. Chambers HF. The changing epidemiology of Staphylococcus aureus? Emerg Infect Dis. 2001;7(2)178-82.

11. Arciola CR, Campoccia D, Baldassarri L, Donati ME, Pirini V, Gamberini S, et al. Detection of biofilm formation in Staphylococcus epidermidis from implant infections. Comparison of a PCR $\square$ method that recognizes the presence of ica genes with two classic phenotypic methods. J Biomed Mat Res. 2006;76(2)425-30.

12. Cooper IR Microbial biofilms: case reviews of bacterial and fungal pathogens persisting on biomaterials and environmental substrata. In: Mendez-Vilas A, editor. Current Research, Technology and Education Topics in Applied Microbiology and Microbial Biotechnology. Badajoz, Spain: Formatex Research Centre; 2011. p. 807-17.

13. Atshan SS, Nor Shamsudin MN, Sekawi Z, Lung Than LT, Hamat RA, Karunanidhi A, et al. Prevalence of adhesion and regulation of biofilm-related genes in different clones of Staphylococcus aureus. BioMed Res Int. 2012;2012:1-10. Article ID 976972.
14. O'Neill E, Pozzi C, Houston P, Humphreys H, Robinson DA, Loughman A, et al. A novel Staphylococcus aureus biofilm phenotype mediated by the fibronectin-binding proteins, FnBPA and FnBPB. J Bacteriol. 2008;190(11)3835-50.

15. Sitkiewicz I, Babiak I, Hryniewicz W. Characterization of transcription within sdr region of Staphylococcus aureus. Antonie Van Leeuwenhoek. 2011;99(2)409-16.

16. Ma Y, Xu Y, Yestrepsky BD, Sorenson RJ, Chen M, Larsen SD, et al. Novel inhibitors of Staphylococcus aureus virulence gene expression and biofilm formation. PLoS One. 2012;7(10)e47255.

17. Gordon RJ, Lowy FD. Pathogenesis of methicillinresistant Staphylococcus aureus infection. Clin Infect Dis. 2008;46(Suppl_5):S350-S9.

18. Davies D. Understanding biofilm resistance to antibacterial agents. Nat revi Drug discov. 2003;2(2)114-22.

19. Chambers HF, Deleo. Waves of resistance: Staphylococcus aureus in the antibiotic era. Nat Rev Microbiol. 2009;7(9)629-41.

20. Grundmann H, Aires-de-Sousa M, Boyce J, Tiemersma E. Emergence and resurgence of meticillin-resistant Staphylococcus aureus as a public-health threat. The Lancet. 2006;368(9538)874-85.

21. Maki DG, Weise CE, Sarafin HW. A semiquantitative culture method for identifying intravenous-catheter-related infection. New Engl J Med. 1977;296(23)1305-9.

22. Bouza E, Alvarado N, Alcalá L, Sánchez-Conde M, Pérez MJ, Muñoz P, et al. A prospective, randomized, and comparative study of 3 different methods for the diagnosis of intravascular catheter colonization. Clin Infect Dis. 2005;40(8)1096-100.

23. Clinical and Laboratory Standards Institute (CLSI), M100-S26. Performance Standards for Antimicrobial Susceptibility Testing: $26^{\text {th }}$ Informational Supplement. Wayne, PA: CLSI; 2015. 256p.

24. Mariana N, Salman S, Neela V, Zamberi S. Evaluation of modified Congo red agar for detection of biofilm produced by clinical isolates of methicillinresistance Staphylococcus aureus. Afr J Microbiol Res. 2009;3(6)330-38.

25. O'Toole GA. Microtiter dish biofilm formation assay. J Vis Exp. 2011(47):pii. 2437.

26. Teh KH, Flint S, French N. Biofilm formation by Campylobacter jejuni in controlled mixed-microbial populations. Int $\mathrm{J}$ Food Microbiol. 2010;143(3)118-24.

27. Martinez-Medina M, Naves P, Blanco J, Aldeguer X, Blanco JE, Blanco, et al. Biofilm formation as a novel phenotypic feature of adherent-invasive Escherichia coli (AIEC). BMC Microbiol. 2009;9(1)202.

28. Wilson K. Preparation of genomic DNA from bacteria. Curr Protoc Mol Biol. 2001; Chapter 2:Unit 2.4. doi: 10.1002/0471142727. mb0204s56.

29. McClure J-A, Conly JM, Lau V, Elsayed S, Louie T, Hutchins W, et al. Novel multiplex PCR assay for detection of the staphylococcal virulence marker Panton-Valentine leukocidin genes and simultaneous discrimination of methicillin-susceptible fromresistant staphylococci. J clin microbiol. 2006;44(3)1141-44.

30. Arciola CR, Campoccia D, Gamberini S, Baldassarri L Montanaro L. Prevalence of cna, fnbA and fnbB adhesin genes among Staphylococcus aureus isolates from orthopedic infections associated to different types of implant. FEMS Microbiol. Lett. 2005;246(1)81-6.

31. Tristan A, Ying L, Bes M, Etienne J, Vandenesch F, Lina G. Use of multiplex PCR to identify Staphylococcus aureus adhesins involved in human hematogenous infections. J Clin Microbiol. 2003;41(9)4465-7. 
32. Le Maréchal C, Seyffert N, Jardin J, Hernandez D, Jan G, Rault L, et al. Molecular basis of virulence in Staphylococcus aureus mastitis. PLoS One. 2011;6(11)e27354.

33. Klein RC, Fabres-Klein MH, Brito MAVP, Fietto LG, Ribon AOB. Staphylococcus aureus of bovine origin: genetic diversity, prevalence and the expression of adhesin-encoding genes. Vet Microbiol. 2012;160(1-2)183-8.

34. Vancraeynest D, Hermans K, Haesebrouck F. Genotypic and phenotypic screening of high and low virulence Staphylococcus aureus isolates from rabbits for biofilm formation and MSCRAMMs. Vet.Microbiol. 2004;103(3)241-7.

35. Peacock SJ, Moore CE, Justice A, Kantzanou M, Story L, Mackie $\mathrm{K}$, et al. Virulent combinations of adhesin and toxin genes in natural populations of Staphylococcus aureus. Infect Immun. 2002;70(9)4987-96.

36. David MZ, Daum RS. Community-associated methicillin-resistant Staphylococcus aureus: epidemiology and clinical consequences of an emerging epidemic. Clin Microbiol Rev. 2010;23(3)616-87.

37. Smuszkiewicz P, Trojanowska I, Tomczak H. Venous catheter microbiological monitoring. Necessity or a habit. Med Sci Monit. 2009;15(2)SC5-SC8.

38. Lombardi S, Scutell M, Felice V, Di Campli E, Di Giulio M, Cellini L. Central vascular catheter infections in a Hospital of Central Italy. New Microbiol. 2014;37(1):41-50.

39. Gupta S, Mallya SP, Bhat A, Baliga S. Microbiology of NonTunnelled Catheter-Related Infections. J Clin Diagn Res. 2016;10(7) DC24- DC28.

40. Al-Tawi ES, Almuhareb AM, Amin HM.. Catheter-related blood stream infection in patients receiving long-term home parenteral nutrition: Tertiary care hospital experience in Saudi Arabia. Saudi. journal of gastroenterology: J Saudi Gastroenterol. 2016;22(4)3048.

41. Worth LJ, Spelman T, Bull JA, Brett JA, Richards MJ. Central line-associated bloodstream infections in Australian intensive care units: Time-trends in infection rates, etiology, and antimicrobial resistance using a comprehensive Victorian surveillance program, 2009-2013. Am J Infect Control. 2015;43(8)848-52.

42. Truong J, Veillette JJ, Forland SC. Outcomes of vancomycin plus a $\beta$-lactam versus vancomycin only for the treatment of methicillinresistant Staphylococcus aureus bacteremia. Antimicrob Agents Chemo. 2018;62(2):pii:e01554-17.

43. Esposito S, Purrello SM, Bonnet E, Novelli A, Tripodi F, Pascale $\mathrm{R}$, et al. Central venous catheter-related biofilm infections: An upto-date focus on meticillin-resistant Staphylococcus aureus. J Glob Antimicrob Resist. 2013;1(2)71-8.

44. Jain SA, Shukla SN, Talati SS, Parikh SK, Bhatt SJ, Maka V. A retrospective study of central venous catheters GCRI experience. Indian journal of medical and paediatric oncology. Indian J Med Paediatr Oncol. 2013;34(4)238-41.

45. Bonnal C, Birgand G, Lolom I, Diamantis S, Dumortier C, L'Heriteau F, et al. Staphylococcus aureus healthcare associated bacteraemia: An indicator of catheter related infections. Med Mal Infect. 2015;45(3)84-8.

46. Costerton JW, Stewart EP Greenberg EP. Bacterial biofilms: a common cause of persistent infections. Science. 1999;284(5418)131822 .

47. Kumari VH, Babu AR, Srinivas D, Siddaiah N, Somanna S. Methicillin-resistant Staphylococcus aureus central nervous system infections-analysis and outcome. Br J Neurosurg. 2015;29(3)413-8.
48. Inomata S, Yano H, Tokuda K, Kanamori, Endo S, Ishizawa C, et al. Microbiological and molecular epidemiological analyses of community-associated methicillin-resistant Staphylococcus aureus at a tertiary care hospital in Japan. J Infect Chemother. 2015;21(10)729-36.

49. de la Gandara MP, Curry M, Berger J, Burstein D, Della-Latta P, Kopetz V, et al. MRSA causing infections in hospitals in Greater Metropolitan New York: Major shift in the dominant clonal type between 1996 and 2014. PLoS One. 2016;11(6)e0156924.

50. Park SH, Kim JK, Park K. In vitro antimicrobial activities of fusidic acid and retapamulin against mupirocin-and methicillin-resistant Staphylococcus aureus. Ann Dermatol. 2015;27(5)551-56.

51. Souli M, Karaiskos I, Galani L, Maraki S, Perivolioti E, Argyropoulou A, et al. Nationwide surveillance of resistance rates of Staphylococcus aureus clinical isolates from Greek hospitals, 2012-2013. Infect Dis. 2016;48(4)287-92.

52. McLaws F, Larsen A, Skov R, Chopra I, O'Neill A. Distribution of fusidic acid resistance determinants in methicillin-resistant Staphylococcus aureus. Antimicrob Agents Chemother. 2011;55(3)1173-6.

53. Decousser JW, Desroches M, Bourgeois-Nicolaos N, Potier J, Jehl F, Lina G, et al. Susceptibility trends including emergence of linezolid resistance among coagulase-negative staphylococci and meticillinresistant Staphylococcus aureus from invasive infections. Int J Antimicrob Agents. 2015;46(6)622-30.

54. Dagnra AY, Hounkpati A, Prince-David M. Fort pourcentage de souches de Staphylococcus aureus résistantes à la méticilline au CHU de Lomé (Togo). Med Mal Infect. 2001;31(1)14-18.

55. Ibrahim, OMA, Bilal NE, Osman OF, Magzoub MA. Assessment of methicillin resistant Staphylococcus aureus detection methods: analytical comparative study. Pan Afr Med J. 2017;27:281

56. Boucher HW, Talbot GH, Bradley JS, Edwards JE, Gilbert D, Rice LB, et al. Bad bugs, no drugs: no ESKAPE! An update from the Infectious Diseases Society of America. Clin Infect Dis. 2009;48(1)1-12.

57. Shlaes DM, Sahm D, Opiela C B Spellberg. The FDA reboot of antibiotic development. Antimicrob Agents Chemother. 2013;57(10)4605-7.

58. Serray B, Oufrid S, Hannaoui I, Bourjilate F, Soraa N, Mliji M, et al. Genes encoding adhesion factors and biofilm formation in methicillin-resistant Staphylococcus aureus in Morocco. J Infect Dev Ctries. 2016;10(8)863-9.

59. Mirzaee M, Najar-Peerayeh S, Behmanesh M, Moghadam MF. Relationship between adhesin genes and biofilm formation in vancomycin-intermediate Staphylococcus aureus clinical isolates. Curr microbiol. 2015;70(5)665-70.

60. Howden BP, Davies JK, Johnson PD, Stinear TP, Grayson ML. Reduced vancomycin susceptibility in Staphylococcus aureus, including vancomycin-intermediate and heterogeneous vancomycinintermediate strains: resistance mechanisms, laboratory detection, and clinical implications. Clin Microbiol Rev. 2010;23(1)99-139.

61. Ghasemian A, Najar Peerayeh S, Bakhshi B, Mirzaee M. The Microbial Surface Components Recognizing Adhesive Matrix Molecules (MSCRAMMs) Genes among Clinical Isolates of Staphylococcus aureus from Hospitalized Children Iran J Pathol. 2015;10(4)258-64.

62. Liu H, Lv J, Qi X, Ding Y, Li D, Hu L, et al. The carriage of the serineaspartate repeat protein-encoding sdr genes among Staphylococcus aureus lineages. Braz J Infect Dis. 2015;19(5)498-502. 